\title{
Examining The Perceptions Of Brand Images Regarding Competing MBA Programs
}

Timothee Hinds, Southeastern Louisiana University, USA Dexter Falgoust, Southeastern Louisiana University, USA

Kerry Thomas, Jr., Southeastern Louisiana University, USA

Michael C. Budden, Southeastern Louisiana University, USA

\begin{abstract}
In today's economic environment, it is crucial to create a strong, consistent brand image within a graduate business program. This study examines the perceptions that students at Southeastern Louisiana University hold about its MBA program and the MBA programs of its main competitors. A focus group was conducted to indentify competitors and factors used to compare MBA programs. A questionnaire was designed and distributed and the results were analyzed using perceptual maps.
\end{abstract}

Keywords: Branding; MBA; Perceptual Mapping; Competitive Environment; Image

\section{INTRODUCTION}

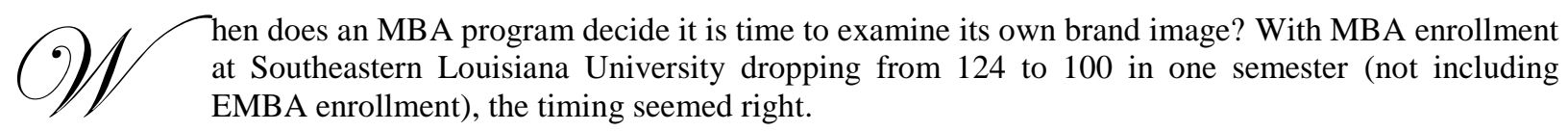

The choice of graduate school program is not a choice that prospective students take lightly. They must go through "a deliberative process of selection" that often takes a lot of time and research. This is a high-involvement activity that acknowledges brand value and differentiation (Schoenfeld \& Bruce, 2005). Therefore, it is essential that MBA and other graduate programs acknowledge their marketability to prospective students. In regard to graduate school marketing, Schoenfeld and Bruce proffer that the attraction of numerous students with certain characteristics should be an integral part of the marketing for an MBA program. Furthermore, customer analyses from empirical research should be conducted by both administrators and marketing professionals to provide the greatest opportunity for the program to succeed in marketing efforts (Schoenfeld \& Bruce, 2005).

There has been minimal empirical research on the effects of marketing on specific graduate school programs, such as MBAs. This may be due to a lack of resources or due to MBA programs' general feeling that marketing to the consumer may not be a priority in their strategy (Schoenfeld \& Bruce, 2005). On the subject of marketing to students, there is a need for business schools to improve their own marketing or stand accused of not practicing what they preach (Nicholls et al., 1995).

As more institutions of higher education become aware of the need for a powerful brand identity that will serve as a powerful identification and recruitment tool, they may succeed in creating a brand strategy that will yield high returns. The successful schools will distinguish themselves among prospective students, thus implementing a brand strategy separate from an overall marketing strategy and appealing to a target audience seeking differentiation in a market flooded with redundancy (Scarborough, 2007). On this subject, Lancendorfer believes higher education institutions must create a consistent, powerful identity that will provide them with a competitive advantage. A university's brand should reinforce its identity and amplify the qualities that set it apart (Lancendorfer, 2007). 
This study develops an empirical method for examining a concise brand image of an MBA program while mapping its position with those of competitors. Perceptual Mapping allows educational administrators to quickly and visually compare important variables as they relate to program identity. It is of paramount importance to convey the findings of perceptual map evaluations to administrators who can make effective changes in the college environment (Mitchell et al., 1994).

\title{
OBJECTIVES
}

The overall objective of this study was to determine the perceptions of the Southeastern MBA program from the perspective of Southeastern's students, their perceptions of its main competitors, and their perceptions of their ideal MBA program based on the following attributes:

\author{
- $\quad$ Expense \\ - $\quad$ Quality of Instruction \\ - $\quad$ Flexibility \\ - $\quad$ Friendly Learning Environment \\ - $\quad$ Ease of Entry
}

During this study, the results of current MBA students were examined separately from the results of the non-MBA students. A secondary objective was to discover the MBA program non-MBA students would most likely choose and to determine which, if any, independent variables (GPA, major, classification, age, or gender) would significantly impact the choice.

\section{METHODOLOGY}

\section{Focus Group}

Determining specific program attributes to measure was difficult. One option was to use the brand personality model proposed by Aaker (1997). The shortcomings of this scale presented by Azoulay and Kapferer (2003) were enough to discourage using Aaker's scale. More concrete terms were deemed necessary to provide useful data to administrators. This seemed arbitrary without polling current MBA students, so a focus group of MBA students was held to determine which other programs they considered when applying to Southeastern and the factors they used to compare their choices. Focus group research is not only done to obtain information but also to provide insight into respondents' feelings, beliefs, experiences, and reactions to questions which other methods fail to discover (Gibbs, 1997).

The focus group consisted of four females and three males - just within the recommended range for the number of participants in a focus group (Gibbs, 1997). Four of the students had undergraduate degrees in business, and five students had undergraduate degrees from Southeastern. The group was first asked to name all other MBA programs to which they applied. Then, they were asked to name all MBA programs to which they sent their GMAT scores. Next, they were asked to name any other MBA programs they considered. From these lists, a discussion revealed the main competitors to the Southeastern MBA program. It was determined the main competitors were Louisiana State University, the University of Louisiana at Lafayette, Tulane University, and the University of New Orleans.

The second half of the focus group session consisted of a discussion about factors used to compare MBA programs to one another. The group generated a large list of factors. From there, the group determined the most important factors on which they based their program choice. The most important factors were expense, quality of instruction, friendliness of the learning environment, ease of entry, and flexibility.

\section{Questionnaire}

The questionnaire was created using Google Documents, and the link to the survey was sent to all Southeastern's MBA students as well as 1,500 non-MBA students by selecting the first email address on each page 
in the search and directories option on the Southeastern website. The response rate from non-MBA students was less than one percent even after two email reminders, so a paper version of the questionnaire was distributed to several undergraduate classes.

The first page of the questionnaire consisted of a series of Likert statements about Southeastern's MBA program and its competitors. The questions were grouped by the statements shown in Table 1, not by university. The universities were listed in each question in alphabetical order (LSU, Southeastern, Tulane, ULL, and UNO). For all questions, except for the ones on familiarity, a statement followed about the respondent's ideal MBA program. The response options for each statement were strongly disagree, disagree, neutral, agree, and strongly agree.

Table 1: Likert Statements Used in the Questionnaire

\begin{tabular}{|l|}
\hline Likert Statements \\
\hline I am familiar with \\
\hline I am familiar with 's MBA program. \\
\hline 's MBA program is expensive. \\
\hline 's MBA program provides a high quality of instruction. \\
\hline 's MBA program provides a friendly learning environment. \\
\hline 's MBA program is flexible. \\
\hline It is easy to get into
\end{tabular}

This table lists the Likert statement used in questions on the first page of the questionnaire.

The only question on the first page not consisting of Likert statements was a multiple choice question on the respondent's student classification. All those answering 'MBA student' were presented with questions on undergraduate university, undergraduate major, undergraduate GPA, age, and gender. All other respondents were presented questions on current college at Southeastern, current GPA, age, gender, and one question asking which MBA program mentioned they most likely would choose to attend with an option to not attend any MBA program.

\section{Perceptual Maps}

Wittenschlaeger and Fiedler proffer that perceptual mapping has been around for thirty years, yet it is still viewed as an innovative technique. Perceptual maps provide high value as decision-making tools and are easy to produce. Mapping procedures utilize available ratings data to provide a competitive scorecard for management (Wittenschlaeger \& Fiedler, 1997).

The responses to Likert statements were strongly disagree, disagree, neutral, agree, and strongly agree. After the responses were coded, several ANOVA tests were run to assure that the mean of at least one MBA program was significantly different from the other means for each factor analyzed. The results showed a level of significance above $99.99 \%$ for every factor. The perceptual maps in this study were created using the bubble chart option in MS Excel. The position of the center of each bubble was calculated by using the means of the factors on each axis as an ordered pair. The size of the bubble is proportionate to the product of the standard deviations of the factors on each axis. The perceptual maps were created representing the MBA respondents separately from the nonMBA respondents.

\section{Correlation Analysis}

In order to determine whether there were any significant relationships between the choice of MBA program and any of the independent variables, cross-tabs were run in SPSS using the Pearson Chi-Square test of independence to recognize significant results. 


\section{FINDINGS}

\section{Familiarity}

Respondents were questioned as to their familiarity of Southeastern's MBA program and that of four other universities (LSU, Tulane, UNO, and ULL). Non-MBA student respondents' were relatively neutral with their familiarity of Southeastern's MBA program. LSU ranked second on familiarity though the majority of students were not familiar with its MBA program. The other three Universities trailed with similar levels of familiarity (or more correctly unfamiliarity). When speaking of familiarity of the entire University for non-MBA students, the Universities are ranked similarly with Southeastern at the top, then LSU, and the other three around the same. The difference with these findings though, is that Southeastern students are strongly familiar with their University as a whole. These students also are fairly familiar with LSU. Yet when speaking of UNO, Tulane, and ULL, results are pretty neutral. Figure 1 displays familiarity with the university overall and its respective MBA program from MBA respondents. Figure 2 displays familiarity with the university overall and its respective MBA program from nonMBA respondents.

Figure 1: Familiarity with Universities and MBA Programs for MBA Respondents

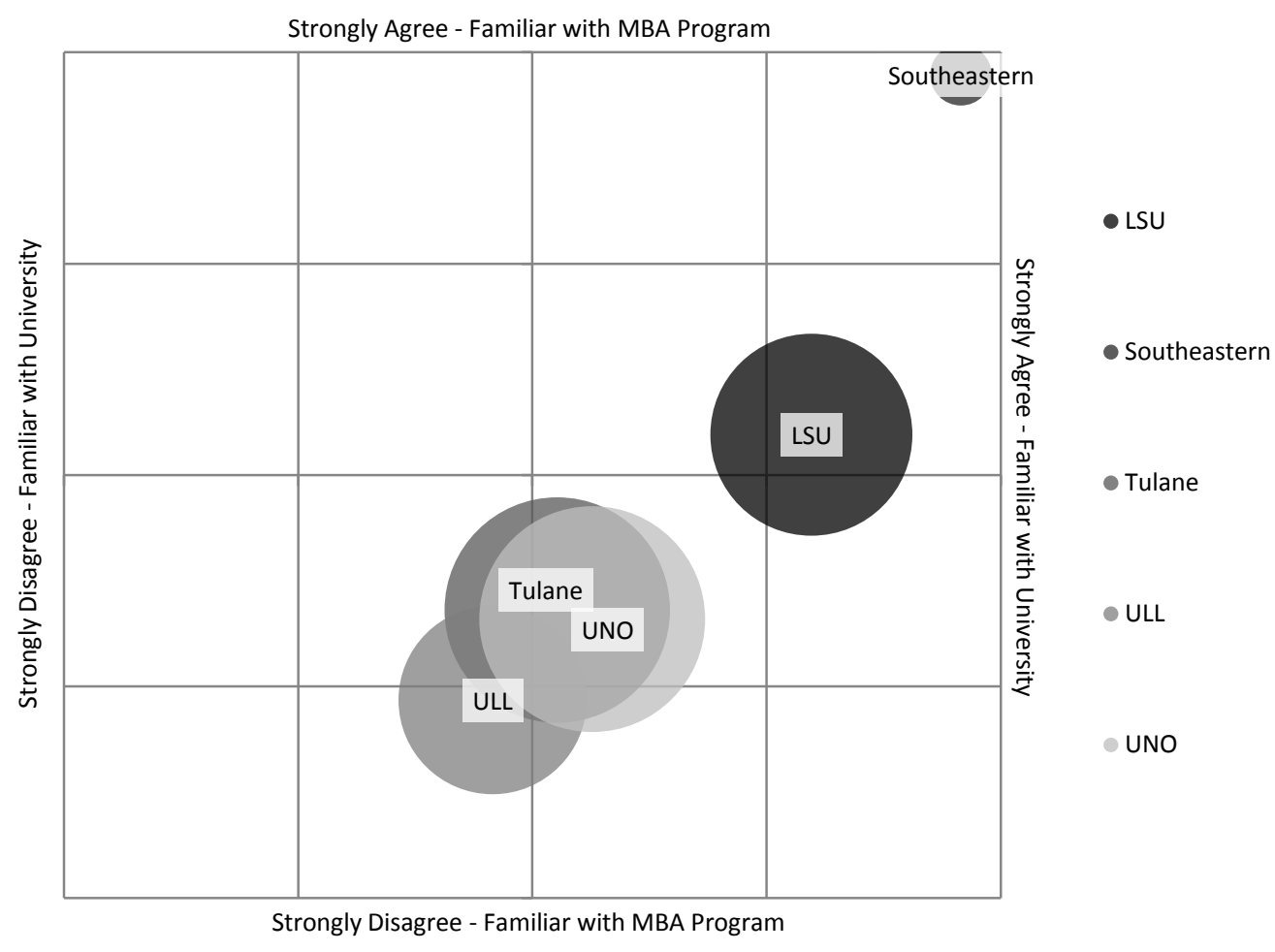

When looking at the results of the MBA respondents (Figure 1), it is seen that the top two Universities are Southeastern and LSU. The biggest difference with these findings is that Southeastern MBA students are strongly familiar with the Southeastern MBA program. Familiarity with LSU's MBA program is moderate rather than low by non-MBA students (Figure 2).

Familiarities of Tulane and UNO's MBA programs are a little higher in these results, yet they are still fairly low in essence. ULL's MBA program familiarity level is also a tad higher among MBA students, yet ULL still remains the lowest rated in both surveys. Familiarity on the University as a whole by MBA students increased a small amount with all Universities except for ULL. Yet ULL's decrease in familiarity was very minor. 
Figure 2: Familiarity with Universities and MBA Programs for Non-MBA Respondents

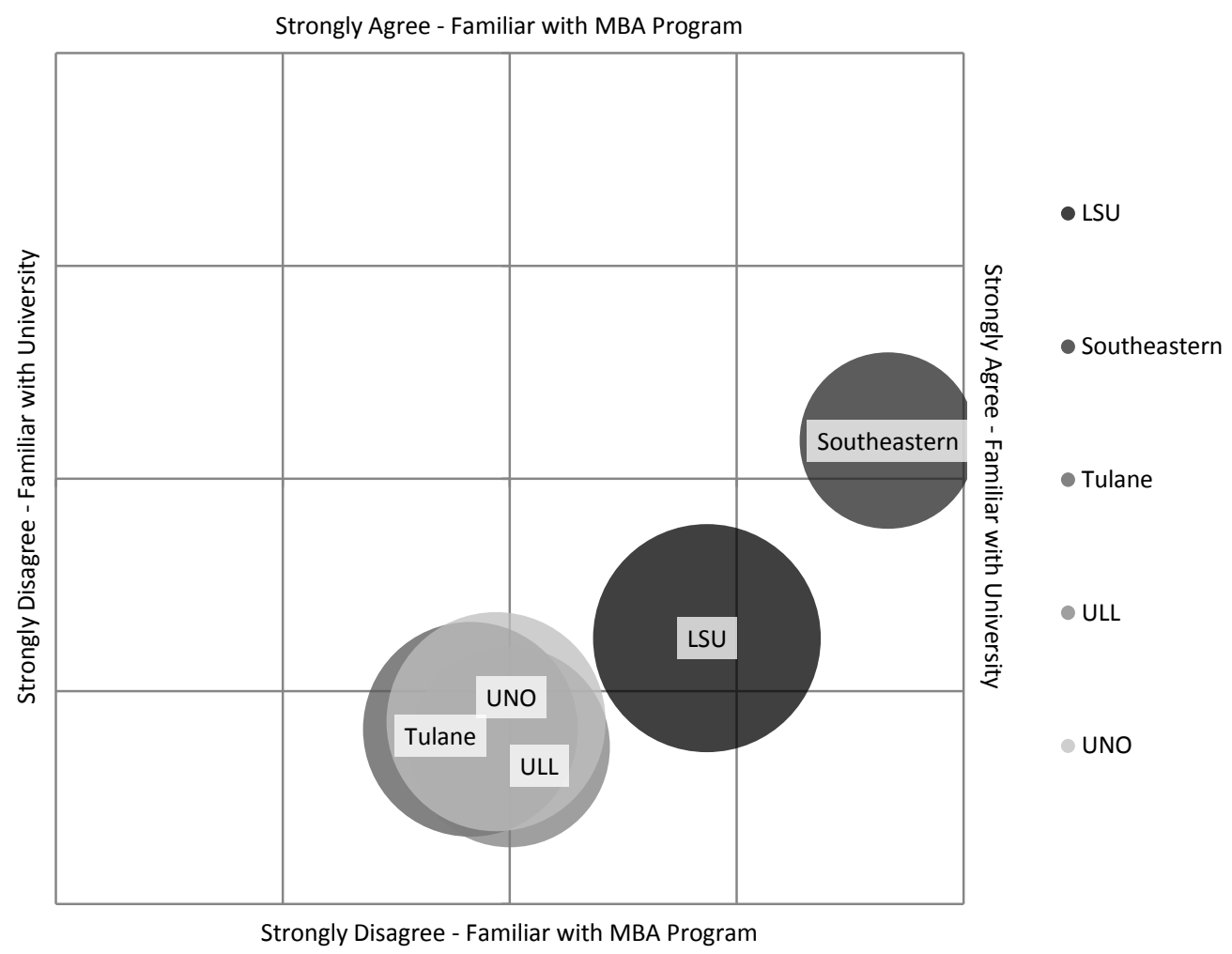

\section{Quality of Instruction and Expense}

In Figure 3, the MBA respondents' perceived quality of instruction and expense were mapped. MBA respondents indicated Southeastern ranks closer in quality of instruction and expense to what their ideal university would provide. Furthermore, respondents' perceptions of two nearby universities, LSU and Tulane, indicate that they are somewhat more expensive and surprisingly are perceived as providing a lower perceived quality of instruction than both Southeastern and their ideal MBA programs. Findings also show that LSU and Tulane MBA programs have perceptions that are similar to one another in both aspects.

MBA respondents were also relatively consistent in their ratings of quality of instruction and expense for Southeastern, Tulane, ULL, and UNO by displaying less variance in their responses. On the other hand, their ratings for LSU and the ideal MBA programs show more variance, as depicted by the area of the circle.

Further, there are two clusters of overlapping variables. ULL, UNO, LSU, and Tulane present a tight cluster where their respective ratings are somewhat close to one another. In the other cluster, respondents overlapped their responses for Southeastern and their ideal MBA program. It is apparent that respondents perceive Tulane, LSU, ULL, and UNO to be significantly separate from their ideal MBA program based on quality of instruction and expense. Relative to Southeastern and the ideal MBA program, they are considered more expensive with a lower quality of instruction. Southeastern, on the other hand, somewhat shares the perceptual space of the ideal program for existing Southeastern MBA students.

Perceptions regarding quality of instruction and expense for non-MBA respondents can be seen in Figure 4. It will be noted that Southeastern's MBA program's quality of instruction and expense levels are closest to the ideal MBA program than are the others. 
Figure 3: Perceptions of Quality of Instruction and Expense for MBA Respondents

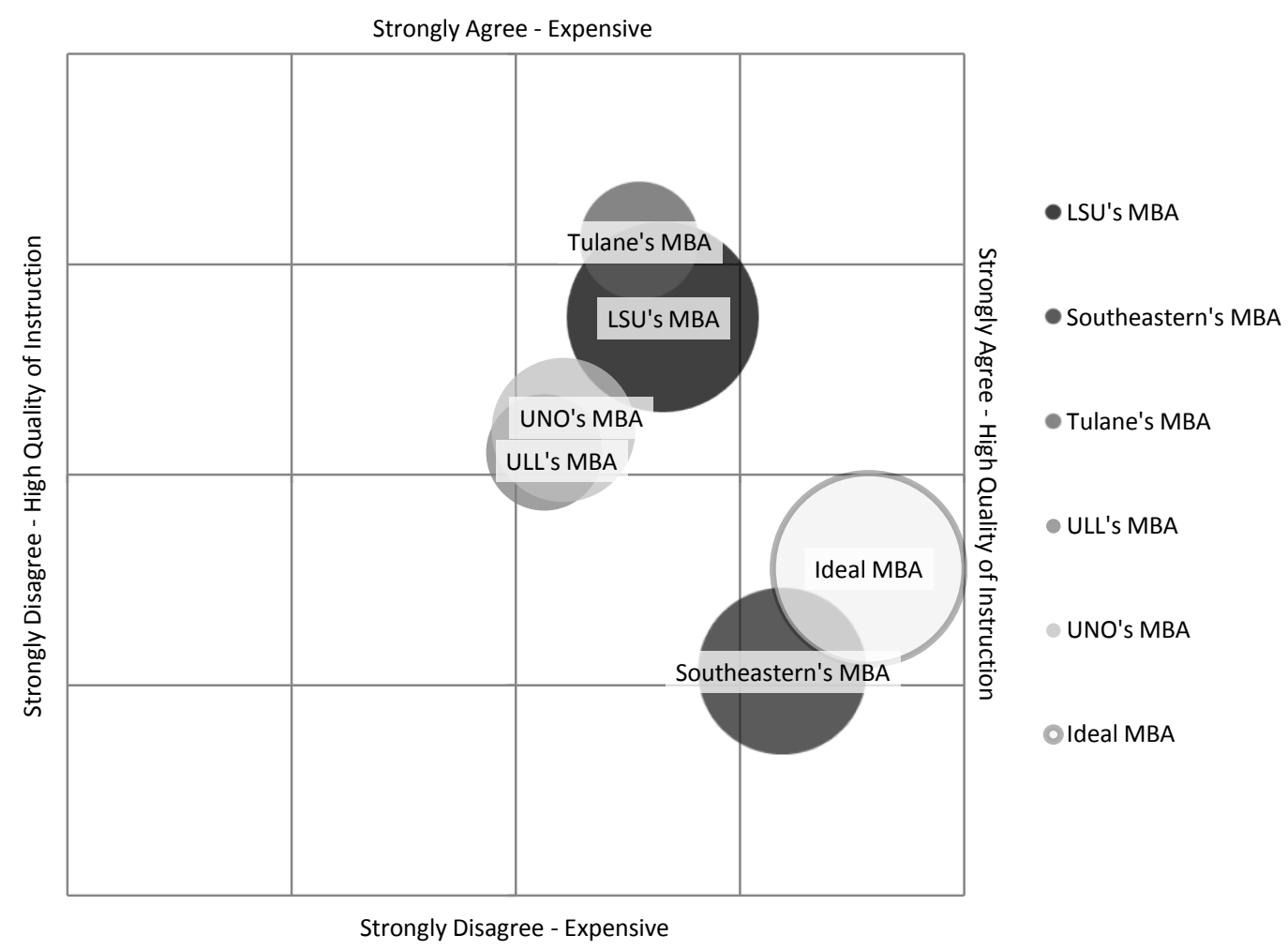

Non-MBA students responded differently to MBA students in their perceptions of quality of instruction and expense for these programs. Non-MBA students perceived the different MBA programs much more closely than MBA students at Southeastern. Again, Southeastern's MBA program closely overlapped with the ideal MBA program, LSU and Tulane were closely perceived, and UNO and ULL were closely rated. Non-MBA students perceived LSU and Tulane as more expensive and categorized the ideal MBA program, Southeastern's, UNO's, and ULL's MBA programs to be very close to one another in price.

The level of instruction at an ideal MBA program is perceived as providing the highest quality of instruction, followed closely by Southeastern. MBA programs of the other universities were perceived closely behind the ideal program and Southeastern's.

In comparing results of quality of instruction and expense from MBA students and non-MBA students at Southeastern, the overall perception is that Southeastern's MBA program ranks closest to their overall ideal program in dimensions of both expense and quality of instruction. Furthermore, it is evident that non-MBAs feel their ideal MBA program is less expensive than Southeastern while current Southeastern MBA students feel their ideal MBA would be more expensive than Southeastern's MBA program. Non-MBA students clustered the different university programs closer to one another than MBA students. MBA students distinctly separated LSU, Tulane, UNO, and ULL in quality of instruction and expense from Southeastern and the ideal MBA program. MBA students at Southeastern perceive that quality of instruction is better and cost is cheaper at Southeastern. Non-MBA students do not differentiate between the factors as much. 
Figure 4: Perceptions of Quality of Instruction and Expense for Non-MBA Respondents

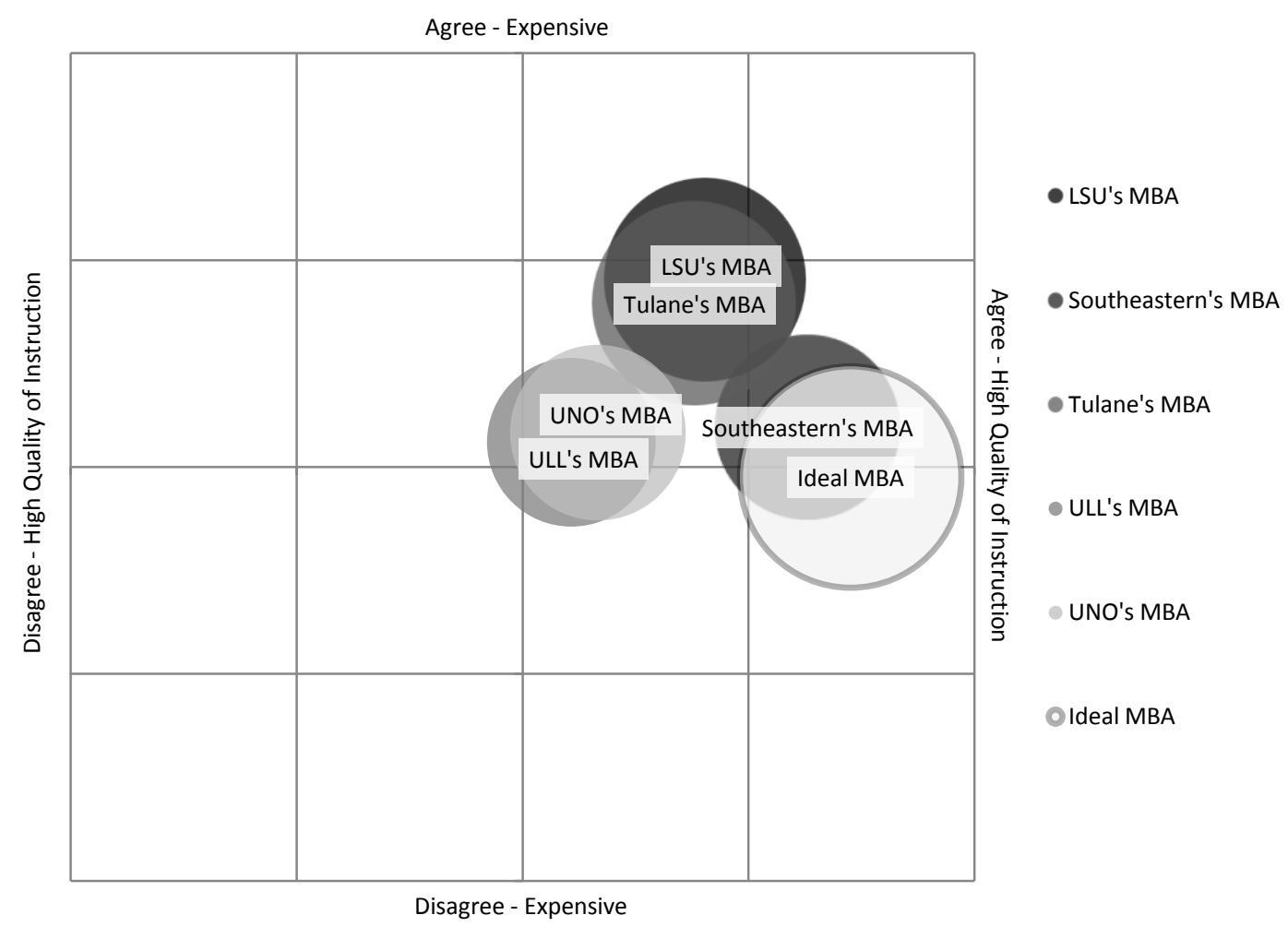

\section{Friendly Learning Environment and Flexibility}

In Figures 5 and 6, perceptual maps help explain how well university MBA programs rated as a friendly learning environment and as a flexible learning environment. Figure 5 measures this perception from an MBA standpoint, while Figure 6 measures the non-MBA perceptions. As before, there is a tendency for Southeastern students to rate Southeastern's MBA program closer to their ideal program than other universities' programs. There is also a tendency for students to group the other universities' programs together.

Southeastern MBA students consider Southeastern as a friendly learning environment. Overall, they strongly agree that their ideal MBA would have a friendly learning environment and perceive Southeastern's MBA program to be pretty close to the friendliness of their ideal MBA. Southeastern students are pretty neutral in their perception of the friendliness of LSU's, Tulane's, ULL's, and UNO's MBA programs, neither strongly agreeing or disagreeing that these university programs have a friendly learning environments. Southeastern MBA students also value flexibility and overall strongly agree that their ideal MBA would be flexible. They perceive Southeastern's MBA program to be almost as flexible as their ideal MBA program. As for other universities' MBA programs, the students perceived LSU's, Tulane's, ULL's, and UNO's levels of flexibility in their respective MBA programs to be fairly neutral. Again, they neither strongly agree nor disagree that these universities' MBA programs are flexible.

Taking both friendly learning environment and flexibility into account, Southeastern MBA students are highly neutral in their perceptions of LSU's, UNO's, Tulane's, and ULL's MBA programs, leading to a central cluster in the perceptual map. Southeastern's and the ideal MBA overlap, and both friendliness and flexibility are highly rated by Southeastern MBA students and perceived to be definitive of Southeastern's MBA program. 
Figure 5: Perceptions of Friendliness of Learning Environment and Flexibility for MBA Respondents

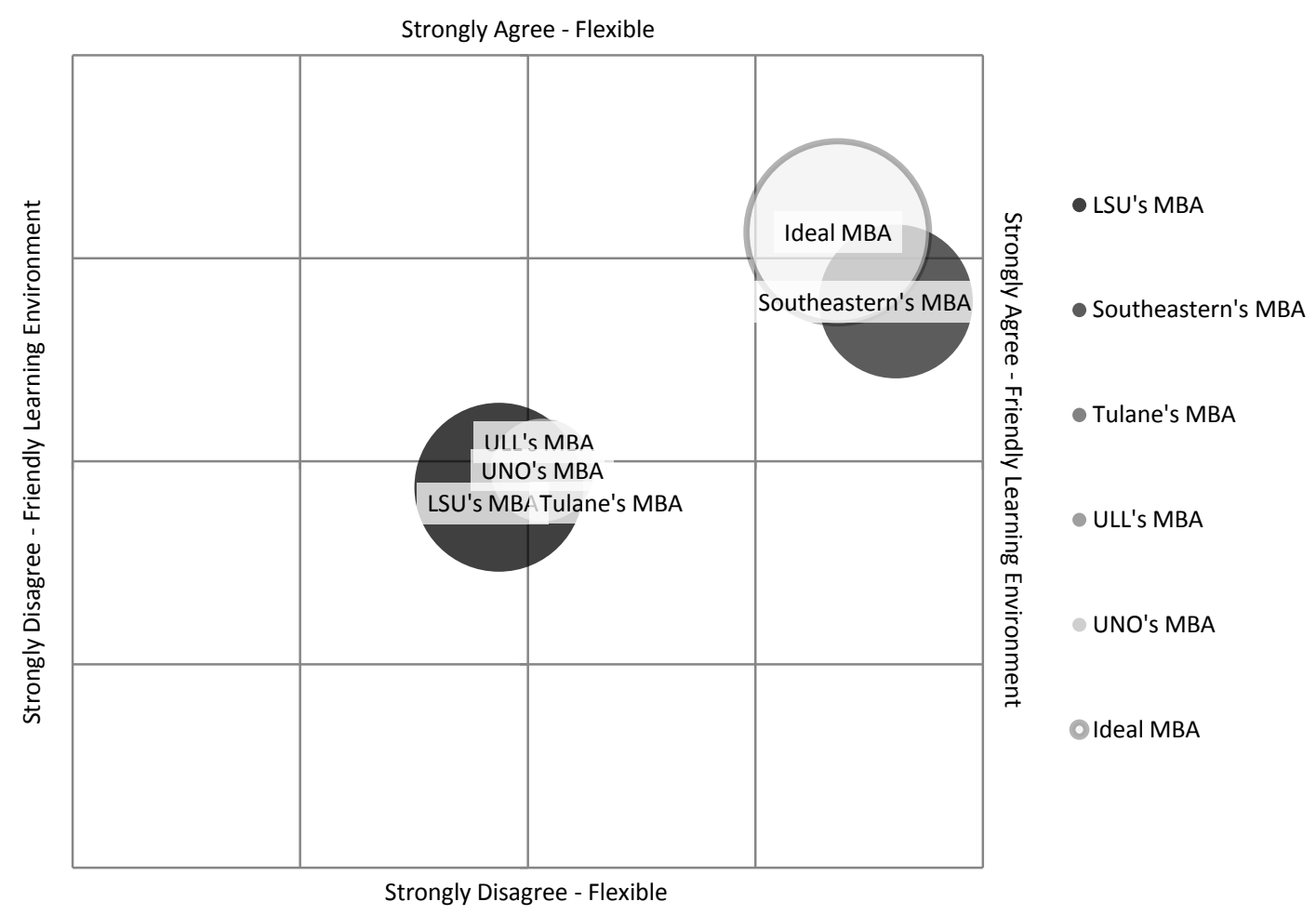

Figure 6: Perceptions of Friendliness of Learning Environment and Flexibility for non-MBA Respondents

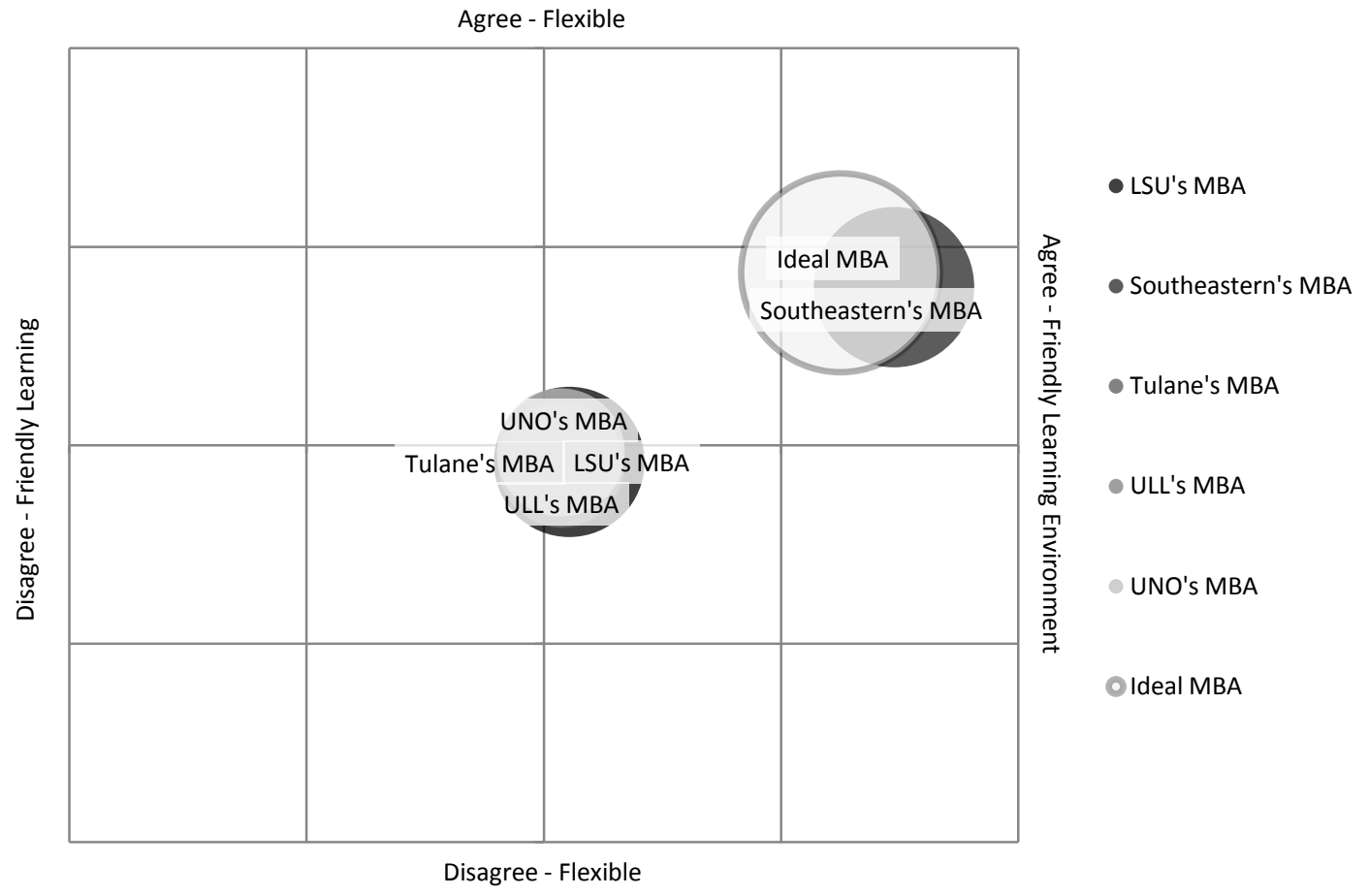


Non-MBA students perceived friendly learning environment and flexibility similarly to the MBA students at Southeastern. They are neutral in their perception of LSU's, Tulane's, ULL's, and UNO's MBA programs, neither agreeing nor disagreeing that these programs are friendly or flexible. As a whole, non-MBA students agree that their ideal MBA program would be flexible and somewhat agree that it would be a friendly learning environment. Again, they perceive Southeastern's MBA program to have a friendlier learning environment than the ideal MBA program and see it to be close to the ideal with respect to flexibility.

Overall, MBA and non-MBA respondents' perceptions of friendly learning environment and flexibility in universities' MBA programs are similar. Both populations cluster LSU's, Tulane's, ULL's, and UNO's MBA programs together in a neutral position. Also, they both tend to overlap Southeastern's and their ideal MBA programs in their perception of both factors. The main difference between Southeastern MBA and non-MBA students' perceptions of friendliness and flexibility is that non-MBA students agree rather than strongly agree about the level of their ideal MBA program's flexibility and friendly learning environment and the level that Southeastern ranks in their perceptions of its flexibility and friendliness. Students in the MBA program at Southeastern strongly agree about the importance of flexibility of their ideal MBA program and the perception of how flexible and friendly Southeastern's MBA program rates.

\section{Quality of Instruction and Ease of Entry}

Figure 7 displays MBA respondents' perceptions of quality of instruction and ease of entry, while Figure 8 displays non-MBA respondents' perceptions of quality of instruction and ease of entry. When looking at the findings of the perceptions of the MBA students on this same matter (Figure 7), the results are nearly identical. There are only two minor differences in the results of these students. One is that the rankings remain constant, but there is a very minor shift to the left for all Universities. Plus, all Universities averages do stay above the neutral area. The next difference is that there is a minor shift to the right for the ideal MBA program meaning that MBA students would like to have a little higher quality of instruction. The results for ease of entry are now looked at. These findings show a different order of rankings.

Figure 7: Perceptions of Quality of Instruction and Ease of Entry for MBA Respondents

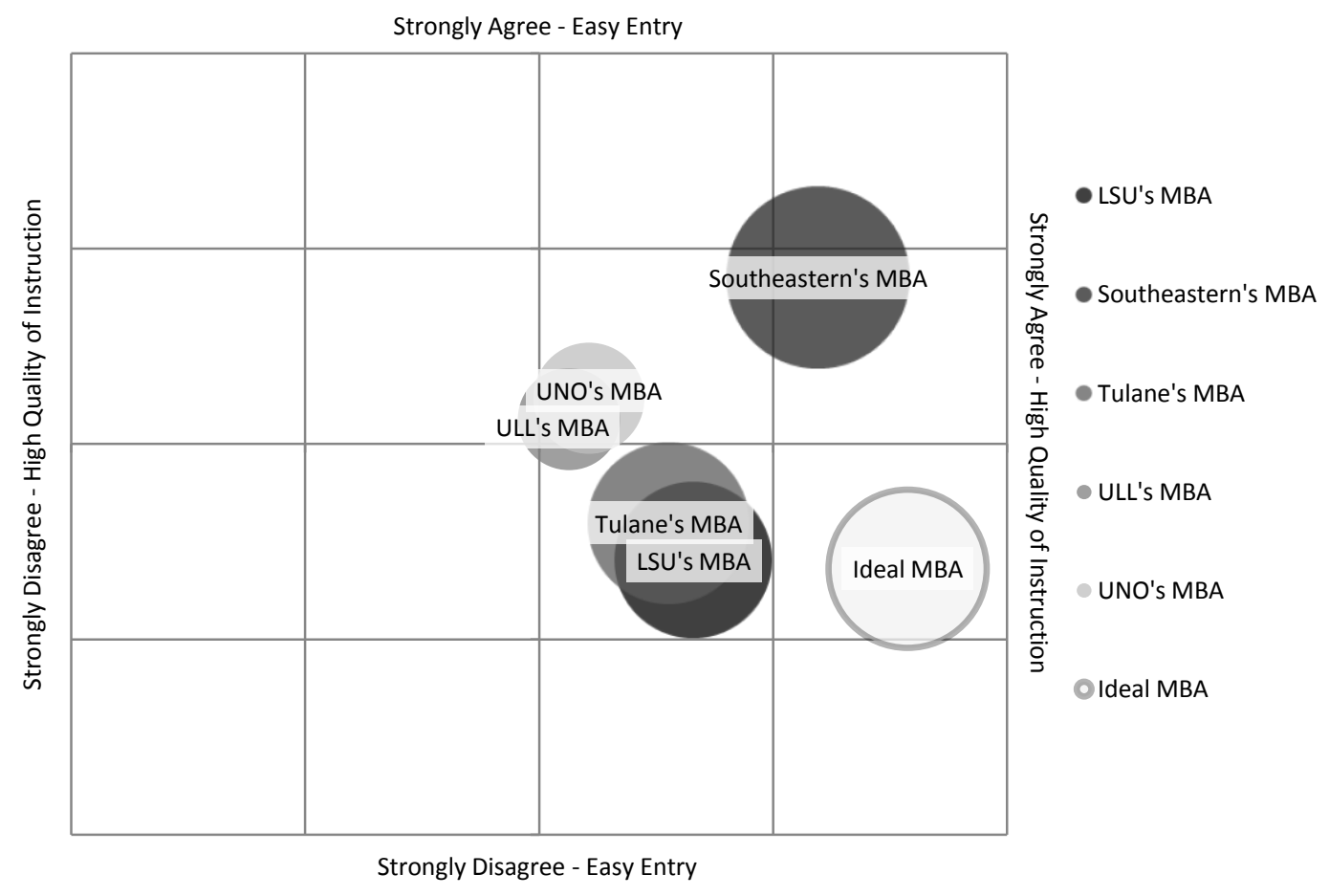


When looking at the results of the non-MBA students (Figure 8), it is shown that Southeastern is at the top with students pretty strongly agreeing that the University's quality of instruction is high. Yet the students do feel that it could be higher, due to the fact that results show the ideal MBA program ranking slightly higher on quality of instruction. LSU's MBA program is thought to be the next highest quality of instruction by these students, with Tulane's following very closely behind. UNO's MBA program ranks fourth in quality of instruction not very far behind Tulane. ULL falls last in the ranking, with their quality of instruction right past the neutral area. The one thing in common with these findings is that none of them are thought to have a low quality of instruction since none of the averages fall below the neutral line in the results.

Figure 8: Perceptions of Quality of Instruction and Ease of Entry for non-MBA Respondents

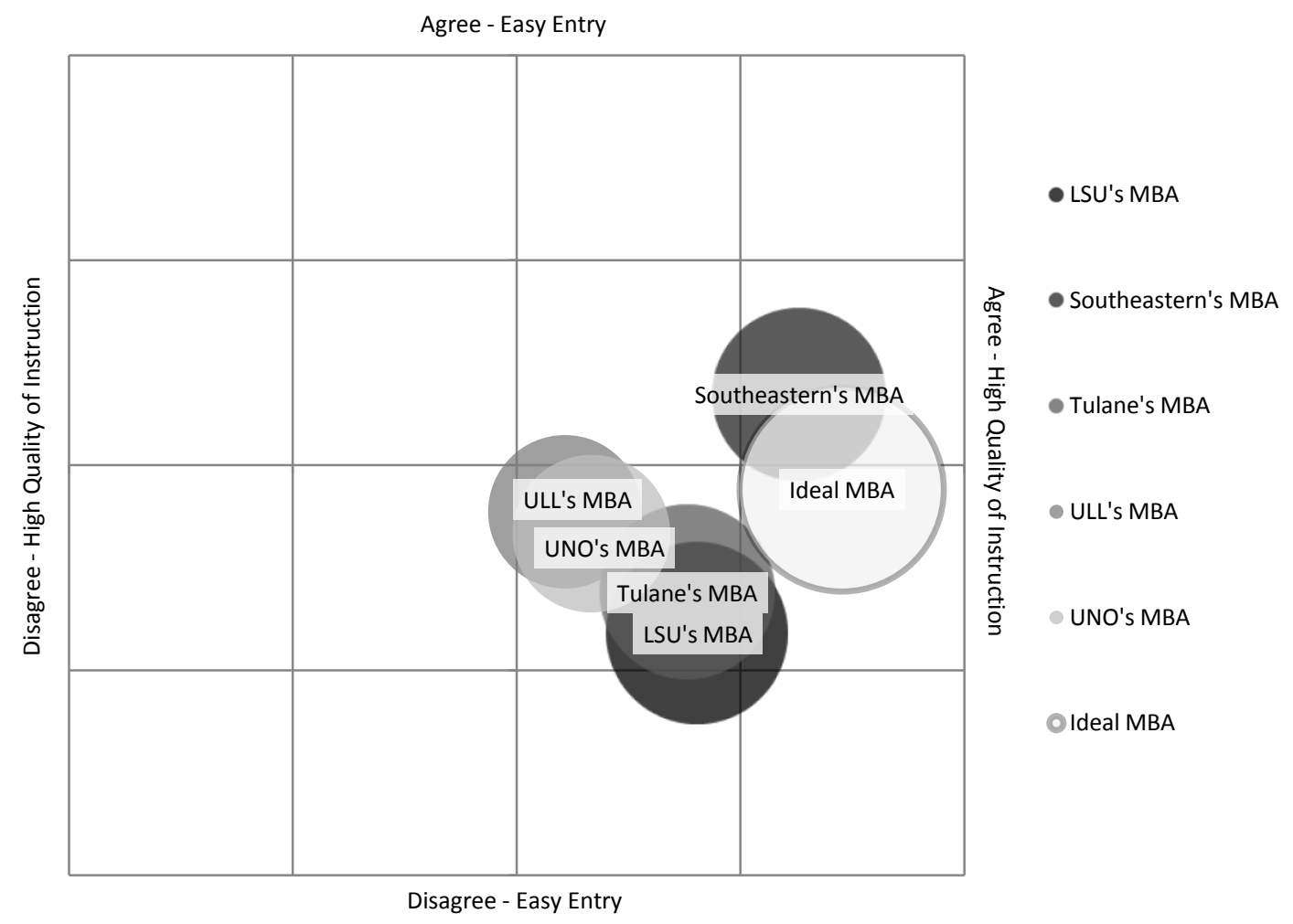

Looking at non-MBA results, Southeastern is rated highest with regard to ease of entry. Yet this is directly above the neutral area which indicates they feel that the ease of entry is not significantly high. The ideal MBA program ranks second right around the neutral area showing that the ease of entry for the non-MBA students' is probably not a big factor for their choice of an MBA program. ULL's program ranks third on ease of entry, but falls right below the neutral line. UNO's program is thought to be a little tougher to get into and ranks fourth on ease of entry right below ULL. Tulane's program shows to be a little tougher to get into, ranking them fifth on ease of entry. LSU's program is thus thought to be the toughest when it comes to ease of entry falling right under Tulane. When looking at the MBA students' results, findings are pretty similar, but there are a few differences. One difference is that ease of entry is thought to be a little higher for all Universities. The highest shifts are UNO and Southeastern. This leaves Southeastern at the top for this comparison also, yet it puts UNO at the second highest level for ease of entry. Both of these schools are above the neutral area respectively with ULL right below UNO. ULL's average is a little above the neutral area with Tulane and LSU falling below the neutral area respectively. The most significant difference in findings for ease of entry is the ideal MBA program being the lowest for ease of entry with the MBA students. This indicates that MBA students' ideal MBA program is perceived to have a moderately tough level of entry. 


\section{Choice of MBA Program}

A Pearson chi-square test was conducted to analyze how gender relates to the MBA program that a Southeastern non-MBA student would be likely to choose and was used to create crosstabs. The null hypothesis that the variables are statistically independent was rejected based on a p-value of .007 in favor of the alternative that the variables are statistically dependent.

Based on the pearson chi-square test, the MBA program that the non-MBA would likely choose would be highly dependent on the non-MBA student's gender. The findings indicate that $65.1 \%$ of Southeastern females would choose Southeastern's MBA program, $16.9 \%$ would not likely enroll in an MBA program, $9.6 \%$ would likely enroll in LSU's MBA program, 4.8\% would likely enroll in UNO's MBA program, and 3.6\% would likely enroll in Tulane's MBA program. Southeastern males, on the other hand, answered differently: $52.9 \%$ would likely enroll in Southeastern's MBA program, 22.4\% would likely enroll in LSU's MBA program, $12.9 \%$ would likely enroll in Tulane's MBA program, 8.2\% would not likely enroll in an MBA program, $2.4 \%$ would likely enroll in ULL's MBA program, and $1.2 \%$ would likely enroll in UNO's MBA program.

Southeastern may be more successful at marketing its MBA program to females than males. To increase enrollment, Southeastern could target their marketing to males in order to increase the likelihood of males enrolling in Southeastern's MBA program. On the other hand, Southeastern's MBA program could market on their increased attractiveness to females than males. Gender difference in perception of MBA quality or business school brand image has been reinforced by other research studies. A study conducted in the U.K. found there were significant differences in perception by age, gender, and employer size of the persons surveyed (Gopalan et al., 2006).

\section{CONCLUSION}

The methodology and format of this study could be used by other MBA programs to keep track of their own non-MBA and MBA students' image perceptions of their MBA program and other graduate programs. This study isolates factors that make MBA programs marketable to students based on the focus group. Other universities should use an individual focus group to account for cultural or systemic differences in their students and their students' perceptions of a competitive university graduate program. Higher education is competitive with universities competing for research funding and competitive faculty salaries to maintain strong graduate programs. To remain competitive, they must develop their brand to improve student, customer, and employer perceptions of the quality of education in the program, and as a result, enhance their marketability. Gender accountability was found to be significant in this study, but other factors should also be considered. MBA and other graduate programs can target demographic groups and other market segments that marketing has not yet tapped and create a more attractive and versatile program. Further, MBA programs should focus on improving factors that prospective students feel are important in a graduate program. Lastly, simply polling non-MBA students on their familiarity with the MBA program at their own university would greatly benefit business schools. If senior and junior undergraduate students in the business college of a university are not familiar with the MBA program at that university, there is cause for concern.

\section{AUTHOR INFORMATION}

Timothee Hinds received his MBA from Southeastern Louisiana University in May of 2010. He is pursuing a career in marketing research and intends to enter a $\mathrm{PhD}$ program in the future.

Dexter Falgoust is an MBA student at Southeastern. His research interests include ethics, education, and methodology.

Kerry Thomas, Jr. after earning his bachelor's degree from LSU he completed the Master of Business Administration program at Southeastern. He is pursuing a career in real estate.

Michael C. Budden is the Mayfield Professor of Marketing at Southeastern. His research interests include marketing ethics, commercial law, retail control and research methodology. 


\section{REFERENCES}

1. Aaker, J.L. (1997). Dimensions of brand personality. Journal of Marketing Research 34, 347-56.

2. Azoulay, A., \& Kapferer, J. (2003). Do brand personality scales really measure brand personality?. Journal of Brand Management, 11(2), 143-155. Retrieved from Business Source Complete database.

3. Gibbs, A. (1997, Winter). Focus groups. Social Research Update. University of Surrey, Guilford. Issue 19.

4. Gopalan, S., Stitts, K. \& Herring III, R.A. (2006). An exploratory investigation of the branding strategies of the top global MBA programs. Journal of International Business Research 5 (2), 49-61.

5. Lancendorfer, K. (2007). The branding of higher education: The great awakening in the hallowed halls of academia. American Academy of Advertising Conference Proceedings, 242. Retrieved from Business Source Complete database.

6. Mitchell, A.A., Sergent, M.T. \& Sedlacek, W.E. (1994). Mapping the university learning environment. ERIC. EBSCO. Web. 21 Apr. 2010

7. Nicholls, J., Harris, J., Morgan, E., Clarke, K. \& Sims, D. (February, 1995). Marketing higher education: The MBA experience. International Journal of Educational Management, 9(2), 31-38.

8. Scarborough, E. (2007). The state of branding in higher education. American Academy of Advertising Conference Proceedings, 242-244. Retrieved from Business Source Complete database.

9. Schoenfeld, G. \& Bruce, G. (2005). School brand images and brand choices in MBA programs. 2005 Symposium for the Marketing of Higher Education (pp. 130-139). Chicago: American Marketing Association.

10. Wittenschlaeger, T.M., and Fiedler, J.A. (1997). Current Practices in Perceptual Mapping. Proceedings of the 1997 Sawtooth Software Conference. Sequim, WA: Sawtooth Software, 259-270. 